\title{
Study of Removal Techniques for Azo Dyes by Biosorption: A Review
}

\author{
Sapna Sharma*, Renu Saxena and Ghanesh Gaur \\ (Department of Chemistry,JECRC University,Jaipur-303905, India)
}

\begin{abstract}
Various dyes present in water have adverse effect on human life, plants and on animals. There are various technologies used to effectively remove these dyes from effluent water. The methodology, advantages and disadvantages of various technologies are discussed in detail. Special emphasis is made on removal of azo dyes using biosorption method. Kinetic procedure of biosorption is also discussed in detail.
\end{abstract}

Key words: Biosorption, dyes, emphasis, methodology, kinetic procedure.

\section{Introduction}

Textile industry is a growing industry in Rajasthan. It requires various types of dyes for dyeing and printing of clothes. Dyeing and printing industries are the main source of water pollution in Rajasthan[1]. Although dyes are present in only small amounts but they are highly detectable and thereby capable of causing various problems. It is reported that there are over 1,00,000 commercially available dyes with a production of over $7 \times 10^{5}$ metric tons per year [2].Dyes are widely used in industries such as textile, paper, plastic and leather for the coloration of products. The effluents emanating from these industries often contain high concentrations of dye wastes. Synthetic dyes can cause considerable environmental pollution and are serious health hazards[34].They cause severe headache, profuse sweating, mental confusion and similar health hazards[5].Therefore removal of dyes from waste water is most desirable.

There are various techniques which have been employed for the treatment of dye bearing industrial effluents. It includes precipitation, adsorption, ion exchange membrane and electro chemical technologies. Literature study show that these technologies are highly expensive, and are not environmental friendly and usually dependent on one of concentration of waste[6].Their initial investment and operational costs are also so high that they can be widely used in developing countries[7-9].Therefore, the search for efficient, eco friendly and cost effective remedies for waste water treatment has been initiated[10].

A dye may be defined as "A colored substance which when applied to the fabrics imparts a permanent color and the color is not removed by washing with water, soap or an exposure to sunlight"[9]. Many dyes have been used in various dyeing process in textile industry and azo dye is one of them. The evolution of the chemistry of dyes began in 1856 with the discovery and industrial production of Mauve, by W.H. Parkin .Prehistoric man had already dyed furs, textiles and other objects with natural substances, mainly of vegetable, but also of animal origin. Further developments extending over many thousands of years led to rather complicated dyeing processes and high-quality dyeing[8]. Most colored textiles and leather articles are treated with azo dyes and pigments[11,12].Due to toxicity and mutagenicity of azo dyes, their removal from effluents has been an urgent challenge[13]. Now a days, research attention has been focused on biological methods for the treatment of effluents[14].Bio adsorption is one of the process that does not require energy and the amount of synthetic chemical.These processes can be carried out in situ at the contaminated site, and also they are cost effective.Among new technologies, utilizing plant residues as adsorbents for the removal of dyes and metal ion from waste water is prominent technology[6]. Removal of dyes by using these bio-adsorbents follows the mechanism of reaction with proteinaceous cellular material. Due to high affinity of the adsorbent for the adsorbate species, the latter is attracted and bound thereby different mechanism. The process continues till equilibrium is established between the amount of solid bound adsorbate species and its portion remaining in the solution. The degree of adsorbent affinity for the adsorbate determines its distribution between the solid and liquid phases. Various sorbents have already been used like mango peel, banana peel, coconut bunch waste, wheat husk, tree barks,tea leaf powder etc.[8].Much research work is being employed in determining new novel biosorbents for removal of azo dyes from effluent water.

\section{Classification Of Dyes}

According to the central pollution control board (CPCB) India, there are approximately a million known dyes and dye intermediates,out of which 5,000 are produced commercially. Based on their use based classification, the dyes are divided into different groups as in Table 1[13]. 
Table 1.Classification of Dyes based on their use ${ }^{[13]}$

\begin{tabular}{|c|c|c|}
\hline Types of Dyes & According to CPCB & According to world Bank \\
\hline Azo dyes & Cotton & Cotton \\
\hline Basic dyes & Acrylic & Paper \\
\hline Direct Dye & $\begin{array}{c}\text { Cotton, paper and synthetics } \\
\text { Dyes }\end{array}$ & Cotton wool or cotton silk \\
\hline Disperse dyes & Polyester & \\
\hline Food dyes & Food, cosmetics & \\
\hline Metal complexes & Cotton & \\
\hline Mordant dyes & Wool & Paints and inks \\
\hline Whitening agent & Plastic, paper, soap & \\
\hline Pigment dyes & Paints and plastics & \\
\hline Reactive dyes & Wool and cotton & \\
\hline Solvent dyes & Synthetics & \\
\hline Sulphur dyes & Cotton and Synthetics & \\
\hline Vat dye & Cotton and Synthetics & \\
\hline
\end{tabular}

\subsection{Classification of dyes based on their Chemical structure}

Dyes may be classified either by their end use or by their chemical structure.According to the different groups dyes can be classified as follows[14].
a).Anthraquinoune dyes
i). Triphenylmethane dyes
b). Vat dyes
c).Indigoid dyes
j).Xanthenes dye
d).Polymethine dyes
k).Sulphur dyes
e).Aryl carboniumdyes
1).Nitrosodyes
f).Phthalocyanin dyes
m).Diphenylamethane dyes
g).Nitro dyes
n).Heterocyclic dyes
o).Miscellaneous dyes

h).Azo Dyes

\subsection{Commonly used Dyes}

On the basis of their application mainly on fibre ,commonly used dyes are given below[14]

- Acid Dyes

- Basic Dyes

- Direct or Substantive Dyes

- Mordant or Adjective Dyes

- Vat Dyes

- Sulphur Dyes

\subsubsection{Azo Dyes}

The name azo comes from azote, the French name for nitrogen. They are compound bearing the functional group $\mathrm{R}-\mathrm{N}=\mathrm{N}-\mathrm{R}^{\prime}$ in which $\mathrm{R}$ and $\mathrm{R}^{\prime}$ can be either alkyl or aryl groups. As a consequence of delocalization, aryl azo compounds have vivid colors specially red, orange and yellow so they are used as dyes and are commonly called as azo dyes. Commonly used azo dyes are Methyl red and Methyl orange[12]

Methyl red (Fig. 1) is an azo dye prepared by diazotization of anthranilic acid followed by reaction with dimethylaniline[11]

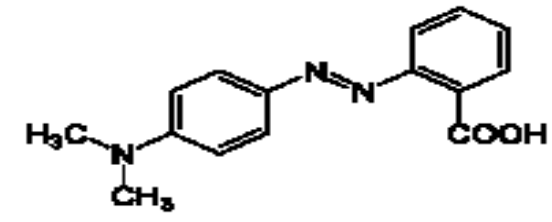

Fig 1: Methyl red

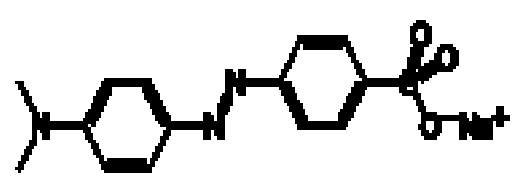

Fig 2: Methyl orange

Methyl red (2, (N-N dimethyl-4-aminophenyl) azo benzene carboxylic acid), also called as C.1. Acid red 2.

It is dark red crystalline powder and red in $\mathrm{pH}$ under 4.4 and yellow in $\mathrm{pH}$ over 6.2. Its properties are summarized as in Table 2.

Table 2. Properties of Methyl red

\begin{tabular}{|c|c|}
\hline \multicolumn{2}{|c|}{ Properties } \\
\hline Molecular formula & $\mathrm{C}_{15} \mathrm{H}_{15} \mathrm{~N}_{3} \mathrm{O}_{2}$ \\
\hline Molar mass & $269.30 \mathrm{~g} \mathrm{~mol}-1$ \\
\hline Density & \multicolumn{2}{|c|}{$0.791 \mathrm{~g} / \mathrm{cm}^{3}$} \\
\hline Melting point & \multicolumn{2}{|c|}{$179-182{ }^{\circ} \mathrm{C}}$, \\
\hline $\mathrm{P}^{\mathrm{H}}$ & \multicolumn{2}{|c|}{$\mathrm{pH}<4.4 \quad \mathrm{pH}>6.2$} \\
& red $\quad$ yellow \\
\hline
\end{tabular}


Methyl orange is sodium 4-[(4-dimethylamino) phenyl diazenyl] benzene sulfonate(Fig. 2). Reactive methyl orange is an anionic dye. It is also called C.1. Acid orange 52. It changes from red to orange yellow at $\mathrm{pH} 3.1$ to 4.4. It is synthesized by reaction of sulfanilic acid, sodium nitrite. The diazonium salt so produced is coupled by dimethylaniline[15].Its properties are summarized as in Table 3.

Table 3.Properties of Methyl Orange

\begin{tabular}{|c|c|}
\hline \multicolumn{2}{|r|}{ Properties } \\
\hline Molecular formula & $\mathrm{C}_{14} \mathrm{H}_{14} \mathrm{~N}_{3} \mathrm{NaO}_{3} \mathrm{~S}$ \\
\hline Molar mass & $327.33 \mathrm{~g} / \mathrm{mol}$ \\
\hline Density & $1.28 \mathrm{~g} / \mathrm{cm}^{3}$, solid \\
\hline Melting point & $>300{ }^{\circ} \mathrm{C}$ (Not precisely defined.) \\
\hline $\mathrm{P}^{\mathrm{H}}$ & $\begin{array}{c}>\mathrm{pH} 4.4 \\
\text { orange }\end{array}$ \\
\hline
\end{tabular}

\subsection{Toxicity of dyes}

As the concentration of textile dye increases in water bodies, it stop the deoxygenating capacity of the receiving water and cut-off sunlight, thereby upsetting biological activity in aquatic life[16]. Also the photosynthesis process of aquatic plants or stage is effected.It has been observed that the chemicals used to produce dyes today are offered highly carcinogenic toxic and explosive effects on our environment.In addition to being toxic, dye effluents also contain chemicals that are carcinogenic, mutagenic or teratogenic to various organisms[17]. This is especially serious because many chemicals can cause damage to genetic material without being expressed immediately .Dyes may affect the photosynthetic activity in aquatic life due to reduced light penetration and may also be toxic to some aquatic life due to the presence of aromatics, metals, etc. in them.It isreported that the mutagenic activity of textile wastewater effluents, using the salmonella/microsome assay and contributed the highest percentage (67\%) of mutagenic effluents[18]. A low level mutagencity of textile/dye industries in the underground water of Sanganer, Jaipur (India) were also investigate.A number of studies have demonstrated mutagenic activity in effluents from textile and dye related industries[19].

\section{Removal Techniques}

There are different methods for the removal of pollutants(dyes,toxic elements etc.) from effluents[20,21]

\subsection{Ion Exchange Technique \\ 3.1.1 Principle}

Ion exchange is technique which involves an exchange of different ions between two electrolytes or between an electrolytic solution and an ion. Ion exchange is a process in which mobile ions from an external solution are exchanged for ions that are electrostatically bound to the functional groups contained within a solid matrix[22].There are different types of ion exchangers. Naturally Occurring Ion Exchangers(Natural inorganic ion exchangers, Natural organic ion exchangers), Synthetic Ion Exchangers (produced by creating chemical compounds with the desired physical and chemical propertiesand can be inorganic or organic based eg. Polystyrene divinylbenzene.)and Composite Ion Exchangers(consist of one or more ion exchangers combined with another material, which can be inorganic or organic and may itself be an ion exchanger[23].

\subsubsection{Ion exchange equilibrium and selectivity}

Ion exchange equilibrium can be described in various terms eg,ion exchange isotherm, the separation factor, the selectivity coefficient, and thermodynamic equilibrium constant[24]. It should be noted that selectivity coefficients are not constant and will vary with the experimental conditions.Changes in physical parameters and of the concentration of functional groups affect the distribution coefficient and can affect the driving force for the ion exchange process. High values of the distribution coefficient are always desirable. The term 'ion exchange capacity' is intended to describe the total available exchange capacity of an ion exchange resin, as described by the number of functional groups on it. This value is constant for a given ion exchange material and is generally given as mill equivalents per gram (mq/g). There are two principle types of ion exchange membranes: heterogeneous and homogeneous[25].Heterogeneous membranes can be prepared by dispersing colloidal or finely ground ion exchange materials throughout an inert thermoplastic binder such polyethylene, polystyrene or synthetic rubber, followed by rolling, compressing or extruding them into discs. Ion exchange processes can be implemented in a variety of ways, including in batches, in columns, in continuous loops and, as part of, or in combination with membrane techniques[26].

Batch operation method can be used with either organic or inorganic media, does not require sophisticated equipment and can be carried out on any scale at ambient temperatures and pressures. It is generally only used for small scale applications for occasional or custom treatments (for up to several hundred litres of liquid)[26]. The most common uses of ion exchange media are as packed beds in vessels or columns. The ion exchange medium is contained inside a steel pressure vessel, with an engineered inlet, outlet and flow 
distribution system to allow liquid to percolate through the bed of the medium at a specified flow rate. Columns are generally used with bead type ion exchange media and can be constructed in a wide variety of sizes and materials to meet the requirements of the system. Column operation is most frequently employed in the cleanup of nuclear power plant primary coolants and auxiliary systems (e.g. fuel pond water) and in liquid radioactive waste treatments[27].The management of waste from ion exchange membrane processes is mostly concerned with the further treatment of the concentrated salt stream, which can be treated by chemical methods or by evaporation or can be immobilized directly.

Electrochemical ion exchange is an advanced ion exchange process that combines the benefits of ion exchange to adsorb ionic species from solution with an electrical driving force that is used to enhance both the adsorption and elution reactions, depending on the direction of the current flow. Electrochemical ion exchange is a separation process that can considered as a cross between electrodialysis and conventional ion exchange[28]. Chemical or electrochemical techniques, followed by ion exchange, for recycle of textile dye wastewater was also studied[29]

\subsubsection{Removal of dyes}

A theoretical model based on ion-exchange reaction between surfactants and dye is used to analyze the experimental data for removal of ionic dyes from water by solvent extraction using reverse micelles[15]. Experiments were conducted by mixing a known quantity of dye in aqueous phase and solvent-containing surfactants in a simple mixer. The removal of different ionic dyes (e.g., eosin yellow, methylene blue, malachite green, methyl orange,) from aqueous phase in the presence of different cationic and anionic surfactants [e.g., sodium dodecylbenzene sulfonate, sodium bis(2-ethylhexyl) sulfosuccinate, hexadecyltrimethylammonium bromide, and cetyl pyridinium chloride] in different solvents (e.g., amyl alcohol, benzyl alcohol, methyl benzoate, and isooctane) were studied by conducting experiments[30]. The percentage removal of dye from aqueous phase increases with the decrease in dye concentration or with the increase in surfactants concentration[15]by ion-exchange methods were very effective and were capable of elevating quality of the treated wastewater effluent to the reuse standard of the textile industry. The azo dyes are one of the most commercially used dyes in textile industry. Due to toxicity and mutagenicity of azo dyes their removal from effluent has been an urgent challenge[18]. Karcher et. al also studied anion exchange resins for removal of reactive dyes from textile wastewaters[30].The apparent thermodynamic parameters were calculated and adsorbents process was found to be spontaneous and exothermic. Ashoka and Inamdar used sugar cane baggases, an agro industry waste, as an adsorbents and as a substitute to activated carbon for the adsorbents of methyl red from aqueous solution[31]. Adsorption of dyes using neem tree bark powder, mango tree bark powder \& locust beans tree bark powder was also studied. The adsorption capacity of adsorbent was explained by adsorbing a known concentration of methyl red and methyl orange at the same operating conditions[32]. It was found that adsorption of dyes increases as the adsorbent concentration increases and decreases as initial concentration of adsorbate increases.

\subsubsection{Advantages of Ion Exchange Technique}

One of the most common treatment methods for such aqueous streams is the use of ion exchange, which is a well developed technique that has been employed for many years for treatment of water.It is used for purification, separation, and decontamination of aqueous and other ion-containing solutions[23].Ion exchange processes can be implemented in a variety of ways, including in batches, in columns, in continuous loops and, as part of, or in combination with membrane techniques.A theoretical model based on ion-exchange is used to analyze the removal of ionic dyes from water by solvent extraction.In this method there is no loss of sorbent on regeneration and this is method is effective [20,21].

3.1.5 Limitations of ion exchange technique

Limitations of ion exchange include the following[33]

- Ion exchange waste is highly concentrated and requires careful disposal,

- generally not effective for low $\mathrm{pH}$,

- generally not effective for high concentrations Fe, Mn, Al and Usually not feasible with high levels of TDS,

- generally not effective for complex mixtures of metals and require Pretreatment for most surface waters,

- suspended solids need to be removed prior to treatment,

- resin regeneration,

- ongoing operational cost.

Ion exchange units are also sensitive to the presence of competing ions[33]. Ion exchange is a very powerful technology to remove impurities from water and other solutions. Many industries depend on ion exchange for the production of extremely pure water. 


\subsection{Coagulation and Flocculation Technique \\ 3.2.1 Principle}

Coagulation-flocculation is a frequently used physicochemical treatment method employed in textile wastewater treatment plants to decolourize textile effluent and reduce the total load of suspensions and organic pollutants [28].All waters, especially surface waters, contain both dissolved and suspended particles. Coagulation and flocculation processes are used to separate the suspended solids portion from the water.The suspended particles vary considerably in source, composition charge, particle size, shape, and density. Correct application of coagulation and flocculation processes and selection of the coagulants depend upon understanding the interaction between these factors. Coagulation and flocculation occur in successive steps intended to overcome the forces stabilizing the suspended particles, allowing particle collision and growth of floc[34].

Coagulation is a gelling or clumping of particle especially in a colloid[34]The first step in coagulation is to destabilizes the particle's charges. Coagulants with charges opposite those of the suspended solids are added to the water to neutralize the negative charges on dispersed non-settable solids such as clay and colourproducing organic substances .

Once the charge is neutralized, the small suspended particles are capable of sticking together. The slightly larger particles formed through this process are called microflocs and they are not visible to the naked eye. Following the first step of coagulation, a second process called flocculation occurs. Flocculation, a gentle mixing stage, increases the particle size from submicroscopic microfloc to visible suspended particles. The microflocs are brought into contact with each other through the process of slow mixing. Collisions of the microfloc particles cause them to bond to produce larger, visible flocs called pinflocs. The floc size continues to build through additional collisions and interaction with inorganic polymers formed by the coagulant or with organic polymers added. Macroflocs are formed and once the floc has reached it optimum size and strength, the water is ready for the sedimentation process[34].

\subsubsection{Coagulants}

An agent that causes a liquid or sol to coagulate is called coagulant. Coagulants are of two main types primary coagulants and coagulant aids. Primary coagulants neutralize the electrical charges of particles in the water which causes the particles to clump together. Coagulant aids add density to slow-settling flocs and add toughness to the flocs so that they will not break up during the mixing and settling processes[18]. Chemically, coagulant chemicals are either metallic salts (such as alum) or polymers. Polymers are man-made organic compounds made up of a long chain of smaller molecules. Polymers can be either cationic (positively charged), anionic (negatively charged), or nonionic (neutrally charged.)[18]. Nonionic disperse dyes have extremely low water solubility; therefore, this class of dyes can be removed effectively by the coagulation-flocculation method [35].

\subsubsection{Study Technique}

Jar Tests-The coagulation-flocculation studies were carried out using the jar test method to determine the optimum $\mathrm{pH}$ range and coagulant and coagulant aid dosages.Each containing $150 \mathrm{~mL}$ of the dye solution, were prepared. $\mathrm{NaOH}(1.0 \mathrm{M})$ or $\mathrm{H}_{2} \mathrm{SO}_{4}(0.1 \mathrm{M})$ was added to each beaker for $\mathrm{pH}$ adjustment. The solutions were stirred for one minute at 60 to $65 \mathrm{rpm}$. Initial $\mathrm{pH}$ (i.e.,pH before coagulation) for each beaker was measured byCyber Scan $510 \mathrm{pH}$ meter (Eutech Instruments, Singapore)and recorded. After adding the desired amount of coagulant $(100$ to $8000 \mathrm{mg} / \mathrm{L})$, the solutions were rapid mixed at 60 to65 rpm for three minutes. Coagulant aid was then added ( 0 to $3.333 \mathrm{mg} / \mathrm{L})$, followed by slow mixing at $10 \mathrm{rpm}$ for oneminute. The flocs that formed were allowed to settle, and the settling time (i.e., the time needed for the flocs to reach half ofthe dye solution depth) was recorded for each beaker. After30 minutes of settling, the solutions containing flocs were filtered through Whatman No. 4 filter papers with a pore size. The supernatants were collected for analysis[36].

The efficiency of removing colour and reducing COD using the coagulation-flocculation method was investigated using mixtures of disperse and reactive dyes.Five combinations of mixed dye solutions were prepared with different ratios of disperse dye (Terasil Blue BGE-01 200\%) to reactive dye (Cibacron Yellow FN-2R), with the final concentration of $1.0 \mathrm{~g} / \mathrm{L}$. In general, the percentage colour removal increased with increased coagulant dosage[37].

\subsubsection{Floc Settling}

velocity of flocs is an important aspect of the coagulation-flocculation process, since it impacts operational cost and the treatment efficiency. The addition of a coagulant aid favours aggregation of the flocs formed by the coagulants, and such a process is needed to increase floc density. To increase significantly the flocs settling velocity ,the flocculation process occurs due to adsorption of the anionic coagulant aid on two or more of the positively charged surfaces. Therefore cationic coagulants were added before the addition of the 
anionic coagulant aid. Flocculation power is also found to increase with the coagulant aid concentration, which increases the floc settling rate[31].The mixing process, and particularly the parameters of rapid mixing, has a great effect on the optimization of the coagulation-flocculation process.

\subsubsection{Mechanism of Coagulation and Flocculation}

In most aqueous suspensions, ionization of surface groups gives an overall negative charge to the particle. The charged particles in suspensions are surrounded by a group of positive ions referred to as the double layer. As particles approach each other the resulting electrostatic repulsion of the double layer prevents flocculation[38]. Increasing the ionic strength of the liquid medium reduces the repulsion until the particles start to aggregate at the critical flocculation concentration. As the charge of these positive ions forming the double layer is increased by adding higher charged ions to system, the double layer gets nearer to the surface allowing the particles to become closer and be attracted by the van der Waals forces. This mechanism is called as doublelayer compression and is often cited for the inorganic flocculating agents such as alum and ferric salts, which add trivalent ions to the system[38].The second mechanism is called as electrostatic mechanism[38]. A highly cationic polymer is adsorbed on a negative particle surface in a flat conformation. The most of the charged groups are close to the surface of the particle. It promotes flocculation by first reducing the overall negative charge on the particle thus reducing intraparticle repulsion. This is called charge neutralization and is associated with reduced electrophoresis' mobility. The positive ions are also attracted to negative regions on the particles, which is called heterocoagulation[38].

The third mechanism is bridging of some individual segments of a very high molecular weight polymer to adsorb on the surface. Large segments of polymer extend into the liquid phase where other segments are adsorbed on other particles, effectively linking particles together with polymer bridges.

The fourth mechanism is called sweep flocculation[38]. Addition of inorganic salts produces hydroxide precipitate which entrains fine particles of other suspended solids as it settles. There are various usual coagulants which are adopted for coagulation like aluminium sulphate (alum), ferrous sulphate, polyelectrolytes, sodium aluminate, magnesium chloride etc[39].

\subsubsection{Electro coagulation Technique}

Since many organic dyes are harmful to human beings, the removal of color from process or waste effluents becomes environmentally important. Reactive dyes,azo dyes, are extensively used in textile industry, due to the ability of their reactive groups to bind to textile fibers by covalent bonds formation.Electrocoagulation (EC) is an alternative technology for wastewater treatment and recovery of valuable chemicals from wastewater. This method involves a sacrificial anode, usually aluminum or iron, where the coagulating metal cations are released in situ as long as an electrical current is applied[40].

Fig.7Arrangements of electrochemical reactor

Treatment of wastewater by EC has been increased as the technology has been improved to minimize electrical power consumption and maximize effluent throughput rates[41].EC, has the advantage of removing small colloidal particles; because of the electric field that sets them in motion. Addition of excessive amount of coagulants can be avoided, due to their in situ generation by electro-oxidation of a sacrificial anode. EC equipment is simple and easy to operate and there is no sludge production.

\subsubsection{Ozonation and chemical coagulation}

Ozonation experiments in a multiple reactor system were conducted to investigate the efficiency of the process in reducing the color and chemical oxygen demand of the textile waste effluents. Ozonation is capable of decomposing the highly structured dye molecules into smaller ones which can be easily biodegraded in an activated sludge process. Hence combination of ozonation, chemical coagulation and the activated sludge processes can provide a very effective means for dealing with this particular type of industrial waste effluent[32].

\subsubsection{Removal of dyes}

Decolourization of Reactive Red 120, Remazol Brilliant Blue, Reactive Green 19 and Reactive Black 5 by ozonation were evaluated to apply for wastewater treatment containing azo dye. The performance colour removal in the single-stage ozonation- biological treatment was also compared with the multi-stage ozonationbiological treatment processes. The following findings were obtained[42]

- Ozonation transforms the functional groups in azo dye to produce more biodegradable by products, which is easily removed by biological treatment. 
- Ozonation is efficient for decolourization of Reactive Red 120 , even with lower ozone dose $\left(0.3 \mathrm{mg} \mathrm{O}_{3} . \mathrm{mg}\right.$ dye-1).

There are some methods used for the treatment of dye-containing wastewater [43]. The The chemical method is to oxidize organic materials by oxidizing agents, such as ozone, $\mathrm{H}_{2} \mathrm{O}_{2}$, UV light or combination of such oxidants that is known as Advanced Oxidation Processes (AOPs)[44]

\subsubsection{Advantages of Coagulation-Flocculation Process}

The main advantage of the coagulation-flocculation method is that the decolourization of the textile wastewater that can be achieved through removal of dye molecules from the dyebath effluents, and not by partial decomposition of dyes, which could produce potentially harmful and toxic aromatic compounds[45] The efficiency of the coagulation-flocculation method depends on the raw wastewater characteristics, $\mathrm{pH}$ and temperature of the solution, the type and dosage of coagulants, and the intensity and duration of mixing[46].The effects of solution $\mathrm{pH}$ and the type and dosage of coagulant on colour removal and COD reduction was also studied[47]The experimental results of this paper showed that treatment with lime alone $(600 \mathrm{mg} / \mathrm{l})$ at $\mathrm{pH}$ value of 11.7 proved to be very effective. Color removal reached $100 \%$ and COD was reduced by $50 \%$. Treatment with magnesium chloride aided with lime at $\mathrm{pH}$ value of 11 removed color completely and reduced the COD value by $40 \%$. Surfactants and dyes with high molecular weights are successfully removed by the coagulation/flocculation processes followed by sedimentation, flotation and filtration, respectively[48].

\subsubsection{Limitations of Coagulation Technique [49,50]}

- In coagulation -flocculation process process a desired amount of chemical (coagulant) is required that create sludge problem .

- In some EC systems, an impermeable formation of oxides film form on the cathode, so efficiency of electrocoagulation csell being effected.

- High conductivity of the waste water suspension is required.

- Gelatinous hydroxide may tend to solubalised in some cases.

- Due to oxidation, sacrificial anode dissolved in the waste water, so need to be regularly replaced.

- The use of electricity may be expensive in some cases.

- The optimum chemical dose required at optimum pHfor effective color removal should be relatively moderate .

\subsection{Microbial decolouration technique \\ 3.4.1Principle}

Microbial decolouration is water treatment (decolouration) through microorganisms like yeast, fungi,bacteria,algae etc. Bioremediation through microorganism has been identified as a cost effective and environment friendly alternative for disposal of textile effluent[51].The environmental problems created by the textile industry have received increased attention for several decades because of contaminated effluents[52] which mainly arise from dyeing processes. Azo dyes are the most widely used dyes and represent over $60 \%$ of the total dyes, they are resistant to degradation[53]. Furthermore, the reductive cleavage of azo linkages is responsible for the formation of amines, which are classified as toxic and carcinogenic. The application of microorganisms for the biodegradation of azo dyes is an attractive alternative to the development of bioremediation processes for the treatment of textile wastewater[54]. Synthetic dyes cannot be efficiently decolourised by traditional biological processes [55].

Microbial decolouration can occur via two principle mechanisms: biosorption and enzymatic degradation, or a combination of both [56]. Both reductases and oxidases are involved in the microbial degradation process. The goal of microbial treatment is to decolourise and detoxify the dye-contaminated effluents[57].

\subsubsection{Biosorption method}

Biomass from algae, yeast, filamentous fungi and bacteria has been used to remove dyes by biosorption[58]. The biosorption capacity of a microorganism is attributed to the heteropolysaccharide and lipid components of the cell wall, which contain different functional groups, including amino, carboxyl, hydroxyl, phosphate and other charged groups, causing strong attractive forces between the azo dye and the cell wall[59].The effectiveness of biosorption depends on the following conditions: $\mathrm{pH}$, temperature, ionic strength, time of contact, adsorbent and dye concentration, dye structure and type of microorganism[60].

\subsubsection{Enzymatic degradation}


Azo dyes are electron-deficient xenobiotic components because of their azo linkage $(-\mathrm{N} \mathrm{N})$, and in many cases, they have sulphonic or other electron-zwithdrawing groups, which generate an electron deficiency and make the dye less susceptible to degradation by microorganisms[61]. Under the appropriate conditions, they can be degraded by reductases. The anaerobic mechanism of microbial degradation of azo dyes to their corresponding amines is initiated by the cleavage of the azo linkage with the aid of an anaerobic azo reductase[62]. Various enzymes that reduce azo linkages have been identified: FMN-independent reductases[63] and sNADPH-dependent reductases[64].

\subsubsection{Factors affecting removal of Azo Dyes}

Microorganisms are sensitive to the presence of chemical substances,such as dyes, high salinity, variations in $\mathrm{pH}$ and high content of organic compound. For bioremediation processes, the most useful microorganisms are those isolated from textile industry-contaminated environments, including soil, effluents and sludge from wastewater treatment plants, because they are adapted to grow in extreme conditions[65].The bio decolouration process is dependent on the many factors.

\subsubsection{Effects of the azo dye structure}

It has been observed that the enzymatic degradation of azo dye is highly influenced by its structure[66].The azo dyes with electron-withdrawing groups are easier to degrade than those with electronreleasing groups, such as $-\mathrm{NH}$-triazine. Therefore, azo dyes that contain more electron-withdrawing groups show faster decolouration.

\subsubsection{Influence of carbon and nitrogen sources}

Carbon and nitrogen sources have an important influence on the extent of decolouration using microorganisms. Different microbial metabolic characteristics lead to differences in the uptake of sources, thus affecting azo dye decolouration[67] Carbon sources have two purposes: as sources of carbon and energy for the growth and survival of the microorganisms and as electron donors, which are necessary for the breakage of the azo bond. Carbon sources are accepted differently by different microorganisms and have an important effect on the extent of decolouration.

\subsubsection{Influence of salinity, dye concentration, $\mathrm{pH}$, temperature and oxygen}

The operation conditions which affect the efficiency of microorganisms to decolourate azo dyes, are the presence of salts, concentration of the dyes, $\mathrm{pH}$, temperature and oxygen. Generally, a sodium concentration above $3000 \mathrm{ppm}$ causes moderate inhibition of most bacterial activities, thus, azo dye removal efficiencies under saline conditions decreaseThe study show that adsorption and enzymatic activity is dependent on the $\mathrm{pH}$ also. As the extent of decolouration is influenced by the $\mathrm{pH}$ of the media, $\mathrm{pH}$ also affects the colour of the solution and the solubility of the dye. Candida tropicalis adsorbs $45 \%$ of Basic Violet 3 at $\mathrm{pH} 3,85 \%$ at $\mathrm{pH} 4$ and $33 \%$ at pH 9[68].

\subsubsection{Biological systems involved in the decolouration of azo dyes}

Different microorganisms have been tested for the decolouration and mineralisation of azo dyes, including algae, yeast, filamentous fungi and bacteria

\section{Decolouration of azo dyes using algae}

The mechanisms of algae decolouration can involve enzymatic degradation, adsorption, or both[69]. Similar to bacteria, algae are capable of degrading azo dyes through an induce azo reductase to break the azo bond, resulting in the production of aromatic amines .High adsorption capacity has been demonstrated at $\mathrm{pH} 2$ using Scenedesmus quadricauda,Chlorella vulgarisand non-viable Spirogyra sp.

\section{Decolouration of azo dyes using yeast}

The mechanisms of decolouration by yeast can involve adsorption[70], enzymatic degradation, or a combination of both. Adsorption on yeast biomass is more efficient at low $\mathrm{pH}[71] \mathrm{as}$ in the case of maximal accumulation of Direct Violet 51 in Candidaalbicans occurs at $\mathrm{pH} 2.5$ and that of Violet 3 in Candida tropicalis occurs at $\mathrm{pH} 4.0[72]$.

\section{Decolouration of azo dyes using filamentous fungi}

The application of filamentousfungi in the decolouration process is an attractive alternativedue to low cost and the possibility of total mineralisation of the dye acc. to Erden et. Al[73].Adsorption is enhanced at $\mathrm{pH}$ $2-3$, which is probably due to electrostatic attractions between charged dye molecules and the charged cell surface.Decolouration is decreased at very high temperatures, which is possibly due to the deactivation of the adsorbent surface or the destruction of some active sites[74].Dye adsorption is dependent on dye concentration. 
At higher concentrations,adsorption get diminished[75]. The percentage of Acid Red 18 and Reactive Black 5 adsorbed by Schizophyllumcommune diminished from $90 \%$ to $27 \%$ and from $92 \%$ to $40 \%$, respectively, when the initial dye concentration was changed from 10 to100 $\mathrm{ppm}$.

\section{Decolouration of azo dyes using genetically modified microorganisms or enzymes}

Bioremediation is an environmentally friendly methodology for the treatment of textile wastewater, but the physicochemical characteristics of the effluents, including $\mathrm{pH}$, the content of $\mathrm{NaCl}$ and other salts, temperature, and the presence of organic compounds,can result in the deactivation of enzymes and microbial cells[74]. Therefore, it is necessary to have more active and versatile enzymes and microorganisms with high stability, high production and low cost that are suitable to meet the requirements of textile industry wastewater treatment.

\subsubsection{Advantages of Microbial Decolouration Technique}

Because of no harmful side effect microbial biodegradation of dyes is a better alternative [76].Some microorganisms, including bacteria, fungi and algae, can degrade or absorb a wide range of dyes [77] .The biological mode of treatment of dye bath effluents offers distinct advantages over the conventional modes of treatment. This method is more economical and leads to less accumulation of relatively harmless sludge. Most importantly, biological treatment of dye bath effluents is ecofriendly. It causes mineralization of dyes to simpler inorganic compounds which are not lethal to life forms.[78]

\subsubsection{Limitations of Microbial Decolouration Technique}

Biodegradation methods such as fungal decolourization, microbial degradation are commonly applied to the treatment of industrial effluents because many microorganisms such as bacteria, yeasts, alges and fungi are able to accumulate and degrade different dyes[74].Biological treatment requires a large land area and is constrained by sensitivity toward diurnal variation as well as toxicity of some chemicals, and less flexibility in design and operation[71].The treatment is incapable of obtaining satisfactory colour elimination with current conventional biodegradation processes. Many organic molecules are degraded, many others like synthetic dyes are recalcitrant due to their complex chemical structure and synthetic organic origin[55].

\subsection{BiosorptionTechnique \\ 3.5.1 Introduction}

Biosorption is a metabolically passive process, means it does not require energy, and the amount of contaminants a sorbent can remove is dependent on kinetic equilibrium and the composition of the sorbents cellular surface[79]. Biosorption is a property of certain types of inactive, dead, microbial biomass to bind and concentrate heavy metals from even very dilute aqueous solutions.

\subsubsection{Principle}

The bio sorption is one of that process which involves a solid phase ( bio sorbent, adsorbent, biological material) and a liquid phase (solvent) containing a dissolved species to be biosorbed ( adsorbate, dye, metal). It is a physiochemical process that occurs naturally in certain biomass which allows it to passively concentrate and bind contaminants onto their cellular structure. If physical forces are involve then dyes will be adsorbed and if chemical forces are involved then metal will be removed[80].

Among various water purification and recycling technologies, adsorption is fast, inexpensive and universal method[81]. The development of low cost adsorbents has led to the rapid growth of research interest in this field. Activated carbon is the most commonly used method of dye removal by adsorption[82].The performance depended on the type of carbon used, the characteristics of waste water and the type of dye. The activated carbon is expensive therefore the carbon has to be reactivated[83].Therefore many researches carried out to search low cost adsorbent which has low density, biological degradability, renewability, show good mechanical properties and is non toxic in nature. Removal of some of the dyes using low cost biosorbents by the process of green technology (biosorption) are as follows.

\subsubsection{Removal of Dyes}

\subsubsection{Removal of Azo Dyes}

The biosorption equilibria and kinetics of Reactive blue 140 were examined using dead fungal biomass of Aspergillus niger HM11 by K.Nanthkumar et. al. ,the results gained from this study were described by Langmuir isotherm model better than Freundlich isotherm models to the biosorption equilibrium data. The maximum adsorption capacity was calculated for dead biomass indicating that dead biomass can be considered as a good sorbent material for Reacive blue 140 solution[84]. 
B.H. Hameed et. al. studied the the ability of coconut bunch waste (CBW), an agriculture waste to remove basic dye (methylene blue) from aqueous solution by adsorption. Batch mode experiments were conducted at $30^{\circ} \mathrm{c}$ to study the effects of $\mathrm{pH}$ and initial concentration of methylene blue (MB).Equilibrium adsorption isotherms and kinetics were investigated[85].The experimental data were analyzed for dye removal by the Langmuir, Freundlich and Tempkin models of adsorption using neem bark and mango bark powder.The adsorption isotherm data were fitted well for MB to Langmuir isotherm and adsorption capacity was found to be monolayer[86]. Ruchi Srivastava and D. C. Rupainwars investigated the low cost biosorbent as a replacement for the current expensive methods of removing dyes from wastewater. Neem bark and Mango bark generated as a wood waste is collected and converted into a powder from and then used as a low-cost adsorbent for removal of dyes from wastewater. Adsorption studies are carried out at different temperatures, $\mathrm{pH}$, initial dye concentrations and adsorbent doses. The adsorption of malachite green (dye) is found to increase with increase in temperature. The linear form of Langmuir and Freundlich models fitted the adsorption[86].

Some of the workers studied the removal of dyes from wastewater using camel thorn plant which is cheap, high efficiency and ecofriendly adsorbent.The study reveals the use of activated carbon prepared from camel thorn plants for the removal of methyl orange (MO) dye from aqueous solution. The results showed that the adsorption of MO increases as the amount of adsorbent increase. The adsorption isotherms (Langmuir and freundlich) were used to analyze the equilibrium data at different temperature. The apparent thermodynamic parameters were calculated and the adsorption process was found to be spontaneous and exothermic[87].

An experimental study was also conducted on the comparative adsorption of dyes Methyl red (MR) and MO using Neem tree bark powder, Mango tree bark powder and Locust bean tree bark powder.The effects of initial dye concentration, adsorbent dosage, temperature and $\mathrm{pH}$ of the medium were investigated. The adsorption capacity of adsorbent was explained by adsorbing a known concentration of MR and MO at the same operating conditions. It was found that adsorption of dyes increases as the adsorbent concentration increases and decreases as initial concentration of adsorbate increases. Neem tree bark, Mango tree bark and Locust bean bark are promising adsorbent which can be used to clean up textile wastes. The adsorption isotherm was also studied and the data obtained fits in well into Langmuir isotherm[88].

H. S. Ashoka and S. S. Inamdar studied the use of sugarcane bagasse, an agro industry waste, to remove MR dye from the waste water. It investigates potential use of sugarcane bagasse pretreated with formaldehyde and sulphuric acid. The adsorption capacity of both formaldehyde treated and sulphuric acid treated bagasse were examined. To compare the performance of treated sugarcane bagasse with commercially available powdered activated carbon, similar experiments were conducted with powder activated carbon. It was observed that adsorption efficiency of sulphuric acid treated bagasse was higher than that of formaldehyde treated bagasse. The data obtain may be useful for designing an economical and optimize treatment process using batch or starred tank reactors for the removal of MR from industrial effluents[89].

The potential of polyalthia longifolia (PL) seed powder to adsorb methylene blue (MB) from aqueous solutions was also investigated through batch experiments. The MB adsorption was found to be dependent on adsorbent dose, contact time, initial MB concentration and temperature. The equilibrium data were described by Freundlich Langmuir and Tempkin isotherm models. The adsorption interaction was found to be spontaneous and exothermic in nature[90].

\subsubsection{Removal of Disperse Dyes}

Adsorption and removal of commercial dyes was studied in aqueous suspensions of fly ash mixtures with a sandy clay loam soil of low organic matter content[91].Batch and column experiments were carried out at equilibrium conditions for concentrations of dyes between 5 and $60 \mathrm{mg} /$ liter. The removed amounts of dyes by adsorption on columns of soil mixture were up to $33.8 \%$ for acid yellow $7,59.4 \%$ for acid yellow $23,84.2 \%$ for direct yellow $28,98.2 \%$ for basic yellow 28 and $60.3 \%$ disperse blue[92].

The effect of different parameters, such as, different doses, $\mathrm{pH}$ and contact time were also investigated. Equilibrium adsorption data for synthesized activated carbon (SAC) were analyzed by Langmuir and Freundlich isotherm. Kinetic studies showed that the adsorption kinetics was more accurately represented by a pseudosecond order model. Among SAC removes $66.47 \%$ of disperse blue at the dose of $0.3 \mathrm{~g}$, whereas the commercial activated carbon removes $54.33 \%$ of disperses blue[93].

\subsubsection{Removal of Reactive Dyes}

Daniela Suteu used commercially powdered activated charcoal for the sorption of reactive dye Brilliant Red HE-3B from aqueous solutions. The effect of solution $\mathrm{pH}$, initial dye concentration, and temperature and sorption time on dye removal was analyzed by the linear, Freundlich and Langmuir models. The kinetic of the sorption followed pseudo-first order and pseudo-second order models. The data showed that the second-order equation was the more intra-particle diffusion is the rate limiting factor[94]. 
A batch system was applied to study the adsorption of reactive dye (RR189) from aqueous solutions by cross-linked chitosan beads. The ionic cross-linking reagent sodium tripolyphosphate was used to obtain more rigid chitosan beads. The desorption data shows that the removal percent of dye RR 189 from the cross-linked chitosan beads is $63 \%$ in $\mathrm{NaOH}$ solutions at $\mathrm{pH} 10.0$. The desorbed chitosan beads can be reused to adsorb the dye and to reach the same capacity as that before desorption[95].

\subsubsection{Removal of Vat Dyes}

The adsorption of a textile dye, namely, Indanthrene Blue RS (C.I. Vat Blue 4) onto smectite-rich clayey rock (AYD) and its sulphuric acid-activated products (AYDS) in aqueous solution was studied in a batch system with respect to contact time, $\mathrm{pH}$, and temperature. The equilibrium adsorption data were analysed using the Langmuir and Freundlich isotherms. The adsorption capacities for AYD and AYDS were found $13.92 \mathrm{mg} / \mathrm{g}$ and $17.85 \mathrm{mg} / \mathrm{g}$, respectively. The effect of temperature on the adsorption was also investigated; adsorption of Indanthrene Blue RS is an endothermic process. This study demonstrates that all the considered adsorbents can be used as an alternative emerging technology for water treatment[96]. Biosludge from a wastewater treatment plant was also able to adsorb colorants, particularly vat dyes, from textile wastewater[97].Autoclaved and resting biosludge showed different adsorption abilities with different types of vat dyes. The adsorption ability of the biosludge increased with an increase in sludge age. The role of some of the waste material such as neem bark, banana peel etc.in the removal of pollutants from aqueous solutions has been reviewed recently and is summarised in table 4.

Table 4. Recent reported adsorption capacities $\mathrm{qm}(\mathrm{mg} / \mathrm{g})$ for waste materials from agriculture and industry for the removal of dye[97-103]

\begin{tabular}{|c|c|c|}
\hline Adsorbent & Dye & $\mathrm{q}_{\mathrm{m}}$ \\
\hline Neem Bark $^{97}$ & Basic red 2 & 1119 \\
\hline Neem Bark $^{97}$ & Basic Blue 9 & 914 \\
\hline Sugar-industry-mud $^{98}$ & Basic blue 9 & 519 \\
\hline Pine sawdust $^{99}$ & Basic red 22r & 398.8 \\
\hline Banana peel $^{100}$ & Methyl orange & 21 \\
\hline Banana peel $^{100}$ & Basic blue 9 & 20.8 \\
\hline Banana peel $^{100}$ & Basic violet 10 & 20.6 \\
\hline Orange peel $^{101}$ & Acid violet & 19.88 \\
\hline Orange peel $^{101}$ & Basic blue 9 & 18.6 \\
\hline Orange peel $^{101}$ & Basic violet 10 & 14.3 \\
\hline Wood sawdust $^{102}$ & Acid blue 25 & 5.99 \\
\hline Sugar cane dust $^{103}$ & Basic green 4 & 4.88 \\
\hline
\end{tabular}

\subsubsection{Methodology of Biosorption}

The various instruments used in this study include pHmeter, spectrophotometer (U.V., visible), water bath, electronic weighing balance; distill water assembly, dryer/ oven, vacuum desiccators, sieve, centrifuge, shaker, thermostat.Other materials employed are different biosorbents.All chemicals used are of analytical grade while experimentation. The technique involve following steps[80]-

\subsubsection{Preparation of biosorbents}

The selected adsorbents will be collected for the present study from various local fields. They will be roughly washed with distilled water to remove the surface adhered particles and water soluble material. Then they will be sliced, spread on trace and oven dried at $105-110{ }^{\circ} \mathrm{C}$ for 24 hours. The dried slice will be ground and sieved to particle size of 1-2 mm. Finally the product will be stored in vacuum desiccators until required. No other chemical or physical treatment will be used prior to adsorption experiment. Scanning electron microscopy (SEM) will be carried out on different adsorbents to check at surface texture before and after adsorption.

\subsubsection{Preparation of dye solution (biosorbate)}

The dye solution will be prepared from dye powder. The stock solution will be prepared by dissolving a weighed quantity of dye in doubly distilled water. The test solution needed for the experiment will be obtained from successive dilution. The concentration of the dye in given solution will be determined by measuring the absorbance value before and after treatment at maximum wavelength using UV spectrophotometer and comparing with the standard calibration curve. The percentage removal of dye will be calculated from $\operatorname{Eq}(1)$.

Removal of dye $(\%)=(\mathrm{Co}-\mathrm{Ce}) \mathrm{Co} / 100$

where $\mathrm{Co}$ is initial concentration of dye, $\mathrm{Ce}$ is the final concentration of dye.

\subsubsection{Biosorption experiment}

Batch adsorption experiments will be carried out at room temperature. A known desired quantity of the 
bio-adsorbent will be added to desired quantity of the dye solution of known concentration and at a known pH in an Erlenmeyer flask at room temperature. The solution will be kept for shaking through rotary orbital shaker. Samples will be withdrawn from the shaker at different time intervals. The adsorbents will be separated from the solution by employing a centrifuge for a period of five minutes. The absorbance of the supernatant solution will be found out by UV spectrophotometer. To estimate the final dye concentration, equilibrium adsorption capacity will be calculated from $\mathrm{Eq}(2)$.

Equilibrium adsorption capacity $\mathrm{q}_{\mathrm{e}}=(\mathrm{Co}-\mathrm{Ce}) \mathrm{V} / \mathrm{W}$

where $\mathrm{Co}$ is initial concentration of dye, $\mathrm{Ce}$ is final concentration of dye, $\mathrm{V}$ is volume of solution, $\mathrm{W}$ is weight of adsorbent.

\subsubsection{Decolorization experiment}

Decolorization experiment will be carried out in response to various factors like agitation speed, agitation time, $\mathrm{pH}$, temperature, adsorbent size, and adsorbent dosages.

\subsubsection{Kinetic studies}

Kinetic studies will also be carried out with different concentration of dyes, while maintaining adsorbent dosage at a constant level. The isotherm results will be analyzed using various isotherm models like Langmuir adsorption model [104], Freundlich adsorption model[105], and Temkin adsorption mode[106].The Langmuir model is based on the assumption that maximum adsorption corresponds to a saturated monolayer of solute molecule on adsorbent surface, with no lateral interaction between the sorbed molecules. The dimensionless constant separation factor $\mathrm{R}_{\mathrm{L}}$, shows the value between 0 and 1 indicate favorable adsorption.

The Freundlich isotherm is an empirical equation employed to describe heterogeneous system. The value of Freundlich constant indicates how favorable is the adsorption process. Tempkin isotherm considered the effect of some indirect sorbate interaction on adsoption isotherm. It suggest that because of these interactions the heat of adsorption of all the molecules in the layer would decrease linearly with coverage.

3.5.5 Adsorption isotherms

The Langmuir adsorption isotherm has been successfully used to explain the adsorption of dyes from aqueous solutions $[107,108]$. The expression of the Langmuir model is given by Eq. (3)

$\mathrm{qe}=\mathrm{Q}_{0} \mathrm{bCe} /(1+\mathrm{bCe})$

where qe $(\mathrm{mg} / \mathrm{g})$ and $\mathrm{Ce}(\mathrm{mg} / \mathrm{L})$ are the amount of adsorbed dye per unit mass of sorbent and un adsorbed dye concentration in solution at equilibrium,respectively. $\mathrm{Q}_{0}$ is the maximum amount of the dye per unit mass of sorbent to form a complete monolayer on the surface bound at high $\mathrm{Ce}$, and $\mathrm{b}$ is a constant related to the affinity of the binding sites $(\mathrm{L} / \mathrm{mg})$. The Langmuir equation can be described by the linearized form:

$\mathrm{Ce} / \mathrm{qe}=1 \mathrm{Q}_{0} \mathrm{~b}+\mathrm{Ce} \mathrm{Q}_{0}$

The linear plot of specific adsorption (Ce/qe) against the equilibrium concentration (Ce) shows that the adsorption obeys the Langmuir model.

$\mathrm{R}_{\mathrm{L}}=1\left(1+\mathrm{bC}_{0}\right)$.

Where $\mathrm{C}_{0}$ is the highest initial concentration of adsorbate $(\mathrm{mg} / \mathrm{L})$, and $\mathrm{b}(\mathrm{L} / \mathrm{mg})$ is Langmuir constant. The value of $R_{L}$ indicates the shape of the isotherm to be either unfavourable $(R L>1)$, linear $(R L=1)$, favorable $(0<\mathrm{RL}<1)$, or irreversible $\left(\mathrm{R}_{\mathrm{L}}=0\right)$. The $\mathrm{R}_{\mathrm{L}}$ values between 0 and 1 indicate favourable adsorption. The Freundlich isotherm is an empirical equation employed to describe heterogeneous systems. The Freundlich equation is expressed as:

$\mathrm{qe}=\mathrm{K}_{\mathrm{F}} \mathrm{C}_{\mathrm{e}}^{1 / \mathrm{n}} \ldots$

where $K_{F}$ and $n$ are Freundlich constants with $K_{F}\left(m g / g(L / m g)^{1 / n}\right)$ is the adsorption capacity of the sorbent and $\mathrm{n}$ giving an indication of how favorable the adsorption process. The magnitude of the exponent, $1 / \mathrm{n}$, gives an indication of the favorability of adsorption. To determine the constants $\mathrm{K}_{\mathrm{F}}$ and $\mathrm{n}$, the linear form of the equation may be used to produce a graph of $\ln (\mathrm{qe})$ against $\ln (\mathrm{Ce})$ :

$\ln \mathrm{qe}=\ln \mathrm{K}_{\mathrm{F}}+(1 / \mathrm{n}) \ln \mathrm{C}_{\mathrm{e}}$

Temkin considered the effects of some indirect sorbate/adsorbate interactions on adsorption isotherms and suggested that because of these interactions the heat of adsorption of all the molecules in the layer would decrease linearly with coverage. The Temkin isotherm has been generally applied in the following form:

$\mathrm{qe}=(\mathrm{RT} / \mathrm{b}) \ln \left(\mathrm{AC}_{\mathrm{e}}\right)$

and can be linearized as:

$\mathrm{qe}=\mathrm{B} \ln \mathrm{A}+\mathrm{B} \ln \mathrm{Ce}$ 
whereB=RT/b,b is theTemkin constant related to heat of sorption $(\mathrm{J} / \mathrm{mol})$; A is the Temkin isotherm constant $(\mathrm{L} / \mathrm{g})$, R the gas constant $(8.314 \mathrm{~J} / \mathrm{molK})$ and $\mathrm{T}$ the absolute temperature $(\mathrm{K})$. The most important parameter to compare is the Langmuir $\mathrm{Q}_{0}$ value since it is a measure of adsorption capacity of the adsorbent.

3.5.6 Advantages of Biosorption

Advantages of biosorption process of a physicochemical system over a biological system are summarized below[109].

(I) less land area required ( to that for a biological system),

(2) lower sensitivity to diurnal variations,

(3) not affected by toxic substances,

(4) potential for significant heavy metal removal,

(5) superior removal of phosphates,

(6) greater flexibility in design and operation and

(7) superior removal of organic waste constituents.

The effective design and application of the adsorption operation in physicochemical treatment requires performance prediction, which in turn requires thorough knowledge of the process itself and of the interplay of control and response variables. Once the process is defined thermodynamically and kinetically, and conditions of specific operation are delineated, mathematical modeling techniques can be employed for forward prediction of performance and adsorber design.

\subsubsection{Limitations of Adsorption process}

The advantages of adsorption over other technologies are that no additional sludge is produced, additional reagents to overcome high alkalinity are not needed, and the $\mathrm{pH}$ of discharged wastewater is unaffected.Though it has some limitations[110].

- Product recovery possibly requiring a special, expensive distillation (or extraction).

- Adsorbent progressively deteriorating in capacity as number of cycles increases.

- Adsorbent regeneration requiring a steam or vacuum source.

- Pre-filtering of gas stream possibly required to remove any particles capable of plugging adsorbent bed.

- Cooling of gas stream require to get usual range of operation temp (below $50 \mathrm{C}^{\circ}$ ).

- Spent adsorbent may be considered a hazardous waste.

- Some contaminants may undergo violent exothermically with adsorbent (explosion danger).

Adsorption is a fundamental process in the physicochemical treatment of municipal wastewaters, a treatment which can economically meet today's higher effluent standards and water reuse requirements. The adsorption process is enhanced by in-situ partial regeneration effected by biological growth on the surfaces of the carbon. Adsorption is integral to a broad spectrum of physical, biological, and chemical processes and operations in the environmental fields.

\section{Conclusion}

This review of literature define different technologies for the removal of various dyes from the effluents. The environmental problems created by the textile industries have received increased attention for several decades because of contaminated effluents, which mainly arise from dyeing processes. Many of the colored textiles and leather articles are treated with azo dyes and pigments. Due to toxicity and mutagenicity of azo dyes, their removal from effluents has been an urgent challenge. There is the search for efficient,ecofriendly and cost effective remedies for waste water treatment. Attempts have been made through the process of biosorption, a green approach, to search novel biosorbents from plant sources as a tool to reduce percentage potential of contaminates in waste water.Still the adsorption process have some limitations like adsorbent regeneration require expensive distillation and it deteriorate progressively as number of cycle increases. The literature survey shows that if low cost adsorbents perform well in removing dye colour they will be used widely in the industrial sector to improve profit and to minimize the cost in efficiencyin the industrial sector. These lowcost biosorbents also offer a lot of promising benefits for commercial purposes in the future. Various researcher are working on removal of dyes using biosorption as a green approach, because of its low cost ,no hazardous chemical formation and it also utilize on various industrial and agricultural wastes.

\section{Acknowledgement}

The author thanks to the President, JECRC University and Ph.D. coordinator, JECRC University for granting a scholarship for their research work. 


\section{References}

[1]. E.A. Clarke and R. Anliker, Springer Organic dyes and pigments ,Handbook of environmental chemistry (anrthpogenic compounds, Part A , 3, $181-21,1980$ ).

[2]. H.Zollinger, Azodyes and Pigments-color chemistry synthesis, properties \& applications of organic dyes \& pigments, Wiley VCH, New York, 1987.

[3]. Z.Aksu and S. Tezer, Biosorption of reactive dyes on green alga Chlorella vulgaris, Process Bio chem. ,40, 2005,1347 - 61.

[4]. E.Forgacsa, T.Cserhatia and G.Oros, Removal of synthetic dyes from waste water : A Review, Environmental International, $30,2004,953-971$.

[5]. K.G.Bhattacharya and A.Sharma, Kinetic and thermodynamicsof methylene blue adsorption on Neem (Azadirachta Indica) leaf powder, Dyes and Pigments, 65(1), 2005,51-59.

[6]. A. Mohammad Ismail, M.Loganathan, and P.A. Gastian Theodar, Effect of bio adsorbents in removal of colour and toxicity of textile and leather dyes, Journal of Eco Biotechnology, 4 (1),2012, 01-10.

[7]. Y.Wang, M.Yang, B.Z.Quan and Y.Hanqing ,Seperation, purification,Technol.,50(1) 2006.

[8]. K.A. Nevine, Removal of reactive dye from aqueous solutions by adsorption onto activated carbon prepared from sugarcane bagasse pith, Desalination, 223( 1-3),2008,152-161.

[9]. M.Rachakornkij S. Rungchuay. and S. Teachakulwiroj, Journal.Science, Technol., 26 (13), 2004.

[10]. Z.Aksu., Application of Bio sorption for the removal of organic pollutant : A review , Process Biochem, 40 ,2005,997 - 1026.

[11]. H.T Clarke.and W.R.Kirner, organic synthesis-47(2),1922.

[12]. Pankaj,T. Bhawna,G goyal,P.K. prem , A Comparative study of Sonosorption of Reactive Red 141 Dye on TiO2 ,Banana Peel, Orange Peel and Hardwood Saw Dust ， Journal of Applicable Chemistry, 14(1),2012,505-511.

[13]. H.A.Erkurt, Biodegradation of azo dyes, Environmental chemistry(Springer, 9,2010).

[14]. O.D.Tyagi and M.Yadav ,Classification of Dyes ,A text book of synthetic dyes (Anmol publication pvt.limited.,ISBN -81-7041349-4,PP66-77,2001).

[15]. P. Pandit,S.Basu, Removal of ionic dyes from water by solvent extraction using reverse micelles, Environmental Science Technology 38(8),2004,35-42.

[16]. H.Zollinger, Azodyes and Pigments- colour chemistry syntheseis,properties and application of organic dyes and pigments, Wiley VCH,New York,1987.

[17]. B.H.Hameed, D.K.Mahmoud and A.L.Ahmed A, Equilibrium modeling and kinetic studies on the adsorption of basic dye by a low cost adsorbents: coconut bunch waste, Journal of Hazardous Materials, 158,2008,65-72.

[18]. Mathur Nupur, Bhatnagar Pradeep, Sharma Prathibha, Review of the Mutagenicity of Textile Dye Products. Universal Journal of Environmental Research and Technology, Open Access Review Article, 2(2), 2012,1-18.

[19]. V.Ponnusami , S.Vikram and S.N.Shrivastva, Guava leaf powder,: novel adsorbent for methylene removal of blue from aqueous solution, Journal of Hazardous material,152, 2008,276-286.

[20]. T. Robinson, G. McMullan, R. Marchant and P. Nigam, Remediation of dyes in textile effluent: a critical review on current treatment technologies with a proposed alternative, Bioresour. Technol. 77,2001, 247-255.

[21]. Monika Kharub, Use of Various Technologies,Methods and Adsorbents for the Removal of,Journal of Environmental Research And Development, 6(3), 2012,879.

[22]. L.A.Bray, R.J. Elovich, K.J. Carson, Cesium Recovery using Savannah River Laboratory Resorcinol-formaldehyde,Ion Exchange Resin, Rep. PNL-7273, Pacific Northwest Lab., Richland, WA 1990.

[23]. A. Dyer, H.J. Hudson, P.A. Williams, Ion Exchange Processes: Advances and Applications, Royal Society of Chemistry, Cambridge, 1993.

[24]. P.R. Gogate, A.B. Pandit, A review of imperative technologies for wastewater treatment:Oxidation technologies at ambient conditions. Adv. Environ. Res., 8,2004,501-551.

[25]. P.R. Danazi , C. Cianetti, Multistage separation of metal ions with a series of composite supported membranes, J. Membr. Sci., $20,1988,215-226$.

[26]. J.C.Farmer et. al., Electrochemical and photochemical treatment of aqueous waste streams, Nuclear and Hazardous Waste Management (Spectrum '96), Vol. 1 Proceedings International Conference Seattle, American Nuclear Society, La Grange Park, IL $1996,435-440$.

[27]. G.A. Martoian ,M.P. Demirchian,G.G. Karamian, The new method of concentrating of liquid radioactive waste by electro dialysis, Radioactive Waste Management and Environmental Remediation,Proceedings International Conference, American Society of Mechanical Engineers, New York,Singapore, 1997,429-430.

[28]. L. Liberti, Ion exchange advanced treatment to remove nutrients from sewage.In: Physicochemical Methods for Water and Wastewater Treatments. Ed. By L.Pawlowski, Elsevier,1982, 225-238.

[29]. S.Karcher, A. Kornmüller, M.Jekel, Anion exchange resins for removal of reactive dyes from textile wastewaters, Water Resources ,36(19),2002,17-24.

[30]. M.I. Aguilar, J.Sáez,M. Lloréns ,A. Soler, J.F.Ortuño, V.Meseguer ,A. Fuentes, Improvement of coagulation flocculation process using anionic polyacryalmide as coagulant aid., Chemosphere, 58,2005, 47-56,2005.

[31]. H.S.Ashoka and S.S. Inamdar, Adsorption removal of methyl red from aqueous solution with treated sugar cane bagasse \& activated carbon- a comparative study, Global Journal of Environmental Research,4(3),2010,175-182.

[32]. M. Koch, A.Yediler ,D. Lienert, G.Insel ,A. Kettrup, Ozonation of hydrolyzed azo dye Reactive Yellow 84 (CI),Chemosphere, 46,2002,109-113.

[33]. R. Harjula ,J. Lehto ,L. Brodkin,E. Tusa , Cs Treat - highly efficient ion exchange media for the treatment of cesium-bearing waste waters, Low Level Waste,Proceedings International Conference Providence,Palo Alto, CA.1997.

[34]. S.Venkat,P.V. Mane, Vijay Babu, Evaluation of performance of Coagulation/Flocculation method for the removal of dyes from aqueous solutions, International conference on current trends in technology, Ahmedabad,2011, 08-10

[35]. W.G. Kuo, Decolorizing dye wastewater with Fenton reagent. Water Resources 26, 1992,881-886.

[36]. R.J. Stephenson, S.J.B. Duff, Coagulation and precipitation of a mechanical pulping effluent.Removal of carbon, color and turbidity. Water Resources, 30, 1996,781-792.

[37]. T.H. Kim , C. Park , E.B. Shin ,S. Kim ,Decolorization of disperse and reactive dye solutions using ferric chloride. Desalination, 161,2004, 49-58.

[38]. Kirk and Othmer, Flocculating agents (Kirk and Othmer Encyclopedia of Chemical Technology,), A Wiley-Interscience, New York, 11, 1994, 68 .

[39]. A. Ozkan, A. M.Yekeler,Coagulation and flocculation characteristics of celestite with different inorganic salts and polymers,chemical engineering process,43(7),2004,873-879. 
[40]. A. Alinsafi , M.Khemis ,M.N. Pons, J.P.Leclerc,A.Yaacoubi, A.Benhammou , A.Nejmeddine , Electro coagulation of reactive textile dyes and textile wastewater, Chemical Engineering and processing ,44, 2005, 461-47.

[41]. B.R. Babu ,A.K. Parande ,S. Raghu,T.P. Kumar, Cotton textile processing: waste generation and effluent treatment. Journal of Cotton Science, 11,2007,141-53.

[42]. Y. C. Chung, C. Y. Chen. Degradation of azo dye reactive violet 5 by TiO2 photocatalysis, Environ Chem Letter, 7(4),2008, 347352 .

[43]. G.M. Walker, L. Hansen, J.A. Hanna, S.J. Allen, Kinetics of reactive dye adsorption onto dolomitic sorbents, Wat Res. , 37,2003, 2081-2089.

[44]. J.W. Choi, H.K. Song, W. Lee, K.K. Koo, C. Han, B.K. Na, Reduction of COD and Colour of Acid and Reactive Dyestuff Wastewater Using Ozone,Korean J. Chem. Eng. ,21(2), 2004,398 - 403.

[45]. V.Golob,A. Vinder ,M. Simoni, Efficiency of the coagulation/flocculation method for the treatment of dye bath effluents, Dyes Pigments ,67,2005,93-97.

[46]. M.Rossini , J.G. Garrido, M.Galluzzo, Optimization of the coagulation flocculation treatment: influence of rapid mix parameters. Water Resources 33,1996,1817-1826.

[47]. F. El-Gohary and A Tawfik, Decolorization and COD reduction of disperse and reactive dyes wastewater using chemicalcoagulation followed by sequential batch reactor (SBR) process, Desalination, 249, 2009,1159-1164.

[48]. M. R. Torres, C. G. Bouzán and M. Crespi, Combination of coagulation-flocculation and nanofiltration techniques for dye removal and water reuse in textile effluents, Desalination, 252, 2010,53-59.

[49]. I.Satish and. Chaturvedi, electrocoagulation : a novel wastewater treatment method, International Journal of Modern Engineering Research,3(1),2013,93-100.

[50]. Pei Wen Wong, Tjoon Tow Teng, Nik Abdul Rahman and Nik Norulaini, Efficiency of the Coagulation-Flocculation Method for the Treatmentof Dye Mixtures Containing Disperse and Reactive Dye, Water Qual. Res. J., 42(1),2007,55-62.

[51]. P.Maulin shah, K.A.Patel ,S.S.Nair andA.M. Darji ,Microbial degradation of textile Dye (remazol Black B) by Bacillus spp.ETL2012,Journal of Bioremediation Biodegradation,4(2),2013,1-2.

[52]. T. Robinson ,G. McMullan ,R. Marchant ,P. Nigam, Remediation of dyes in textile effluent: a critical review on current treatment technologies with a proposed alternative. Bioresources Technology,77,2001,247-55.

[53]. R. Butnaru, Wastewater characteristics in textile finishing mills. Journal of Environmental Engineering Management ,7,2008,859-64.

[54]. N.Puvaneswari, J.Muthukrishnan ,P. Gunasekaran, Toxicity assessment and microbial degradation of azo dyes. Indian Journal Exp Biol,44,2006,618-26.

[55]. M.Ghoreishi ,R. Haghighi, Chemical catalytic reaction and biological oxidation for treatment of non-biodegradable textile effluent, Chemistry Engineering Journal, 95,2003,163-9.

[56]. Y.Wu ,T. Li ,L. Yang, Mechanisms of removing pollutants from aqueous solutions by microorganisms and their aggregates: a review, Bioresources Technology,2012,107-108.

[57]. S.Phugare, P.Patil,S. Govindwar,J. Jadhav ,Exploitation of yeast biomass generated as a waste product of distillery industry for remediation of textile industry, International Biodeterioration and Biodegradation ,64,2010,716-26.

[58]. A.Bhatnagar ,M. Sillanpaa, Utilization of agro-industrial and municipal waste materials as potential adsorbents for water treatment: a review, Chemical Engineering Journal,157,2010,277-96.

[59]. V. Vitor , C.R.Corso, Decolorization of textile dye by Candida albicans isolated from industrial effluents. Journal of Indian Microbiolial Biotechnology,35,2008,1353-7.

[60]. S.T.Ambrosio, J.C. Vilar Junior, C.A.A. Da Silva , K.Okada, A.E.Nascimento , R.L. Longo,A biosorption isotherm model for the removal of reactive azo dyes by inactivated mycelia of Cunninghamella elegans UCP542. Molecules,17,2012,452-62.

[61]. A.B. Santos dosF.J. Cervantes, J.B.Van Lier, Review paper on current technologies for decolourisation of textile wastewaters: perspectives for anaerobic biotechnology. Bioresources Technology,98,2007,2369-85.

[62]. S.Burger,A. Stolz, Characterisation of the flavin-free oxygen-tolerant azoreductase from Xenophilus azovorans KF46F in comparison to flavin-containing azoreductases. Applied Microbiolial Biotechnology,87,2010,2067-76.

[63]. T. Ooi T.,T. Shibata ,R. Sato ,H. Ohno ,S. Kinoshita ,T.L. Thuoc , An azoreductase aerobic NADH-dependent flavoprotein discovered from Bacillus sp.: functional expression and enzymatic characterization. Applied Microbiolial Biotechnology, 75,2007,377-86.

[64]. G.Liu ,J. Zhou ,H. Lv ,X. Xiang ,J. Wang ,M. Zhou et al. Azoreductase from Rhodobacter sphaeroides AS1.1737 is a flavodoxin that also functions as nitroreductase and flavin mononucleotide reductase. Applied Microbiolial Biotechnology 76,2007,1271-9.

[65]. Q.Yang and N.Yu, Degradation of synthetic reactive azo dyes and treatment of textile wastewater by a fungi consortium reactor. Biochemistry Engineering Journal, 43,225-30, (2009)

[66]. R.Sawhney, A.Kumar , Congo Red (azo dye) decolorization by local isolate VTII inhabiting dye effluent exposed soil., International Journal of Environment Science, 1,2011,1261-7.

[67]. S.Moosvi , X.Kher ,D. Madamwar, Isolation, characterization and decolorization of textile dyes by a mixed bacterial consortium JW-2. Dyes Pigments, 74 ,723-9, (2007)

[68]. Das, D.Charumathi ,N. Das, Bioaccumulation of the synthetic dye Basic Violet 3 and heavy metals in single and binary systems by Candida tropicalis grown in a sugarcane bagasse extract medium: modelling optimal conditions using response surface methodology (RSM) and inhibition kinetics. Journal of Hazardous Materials, 186,2011,1541-52.

[69]. N. Sivarajasekar, R. Baskar, V.Balakrishnan, Biosorption of an azo dye from aqueous solutions onto Spirogyra, Journal of Univ Chem Technol Metal,44,2009,157-64.

[70]. I. L.F.T.Safarik, M. Rego, Borovska, E. Mosiniewicz-Szablewska, F. Weyda, M. Safarikova, New magnetically responsive yeastbased biosorbent for the efficient removal of water-soluble dyes. Enzyme Microbiol Technol,40,2007,1551-6.

[71]. Q.Husain, Peroxidase mediated decolorization and remediation of wastewater containing industrial dyes: a review ,Rev Environmental Science Biotechnol,9,2010,117-40.

[72]. D.Charumathi ,D. Nilanjana, Bioaccumulation of synthetic dyes by Candida tropicalis growing in sugarcane bagasse extract medium. Advance Biology Res,4,2010,233-40.

[73]. E. Erden,Y. Kaymaz ,N.K. Pazarlioglu, Biosorption kinetics of a direct azo dye Sirius Blue K-CFN by Trametes versicolor. Electron Journal Biotechnol,14,2011,1-10.

[74]. G. McMullan, C. Meehan, A. Conneely, N.Kirby, T.Robinson, P.Nigam, I.M. Banat, R. Marchant, W.F.Smyth, Microbial decolourisation and degradation of textiles dyes, Application Microbial Biotechnology, 56, 2001,81-87.

[75]. S. Renganathan, W.R.Thilagaraj, L.R.Miranda, P.Gautam,M. Velan, Accumulation of Acid Orange 7 Acid Red 18 and Reactive Black 5 by growing Schizophyllum commune. Bioresour Technol,97,2006,2189-93. 
[76]. SY An ,SK Min ,IH Cha ,YL Choi,YS Cho, CH Kim ,YC Lee , Decolorization of triphenylmethane and azo dyes by Citrobacter sp., Biotechnol. Lett., 24, 2002,1037-1040.

[77]. T. Robinson, G.McMullan ,R. Marchant ,P. Nigam, Remediation of dyes in textile effluent: a critical review on current treatment technologies with a proposed alternative, Bioresour. Technol., 77,2001, 247-255.

[78]. K. Kapdan, M.Tekol ,F. Sengul, Decolorization of simulated textile wastewater in an anaerobic-aerobic sequential treatment system, Proc Biochem ,38,2003,1031-7.

[79]. F. Kargi andS. Ozmihci, Biosorption performance of powdered activated sludge for removal of different dyestuffs, Journal of Microbiology and Technology, 35, 2004, 267-271.

[80]. A.K. Bajpai and M. Rajpoot, Adsorption technique - A Review, Bose Memorial Research Laboratory,Journal of Scientific and Industrial Research ,58,1999, 844-860.

[81]. L. Ali and V.K. Gupta, Nature Protocol, US National library of medicine, National institute of health, 1(6),2006,2661-7.

[82]. N.M. Nasse and El. Geundi, Metal Journal of Chemistry, Technol. Bio technol, 50, 1991,257(1991).

[83]. S.A.B. Figueiredo and R.A. Loureiro, Journal of Metal Separation and Purification - Technol, 20, $2000,129$.

[84]. K.Nanthkumar ,K. Karthikeyan and P. Laxmana, Investigation of Biosorption of reactive blue 140 by dead biomass of Aspergillus Niger HM1 1-kinetics and isotherm studies, Global Journal of Biotechnology and Biochemistry, 4 (2), 2009,169-178.

[85]. B.H. Hameed, D.K. Mahmoud, A.L. Ahmed, Equilibrium modeling and kinetic studies on the adsorption of basic dye by a low cost adsorbents: coconut bunch waste, Journal of Hazardous Materials, 158,2008,65-72.

[86]. R.Shrivastva , D.C.Rupainwar , A comparative evaluation for adsorption of dye on neem bark andmango bark powder, Indian journal of chemical technology, 18,2011, 67-75.

[87]. F.Mogaddasi,M.M. Heraui ,M.R. Bozorgmehr ,P. Ardalan ,T. Ardalon, Kinetic and thermodynamic study on the removal of methyl orange from aqueous solution by adsorption on to camel thorn plant, Asian Journal of Chemistry, 22 (7), 2010,5093-5100,

[88]. P.DIM.Egwuonwu, Adsorption of methyl red and methyl orange using different tree bark powder, Academic Research International, 4(1),2013, 330-338.

[89]. H.S. Ashoka ,S.S. Inamdar, Adsorption removal of methyl red from aqueous solution with treated sugar cane bagasse \& activated carbon- a comparative study, Global Journal of Environmental Research,4(3),2010,175-182.

[90]. K.S. Mundhe, A.B. Gaikwad,R.C. Torane,N.R. Despande ,R.V. Kashalkar, Adsorption of methylene blue from aqueous solution using Polyalthia longifera (Ashoka) seed powder, Journal of Chemical and Pharmaceutical Research ,4(1),2012, 423-436

[91]. T.A. Albanis ,D.G. Hela,T.M. Sakellarides ,T.G. Danis, Removal Of Dyes From Aqueous Solutions by Adsorption on Mixtures of Fly Ash and Soil in Batch and Column Techniques, global Nest: the International Journal, Vol 2( 3), 2000, $237-244$.

[92]. Y.H. Magdy and A.A.M. Daifullah, Adsorption of a basic dye from aqueous solutions onto sugar-industry mud, Waste Management, 18,1998,219-226.

[93]. F. Ahmed, Halbus,H. Zahraa, Athaba,H. Falah Hussein, Adsorption of Disperse Blue Dye on Iraqi Date Palm Seeds Activated Carbon, Internatinal Journal of Chemical science Sci., 11(3), 2013,219-1233.

[94]. Daniela Suteu, Doina Bilba, Equilibrium and Kinetic Study of Reactive Dye Brilliant Red HE-3B Adsorption by Activated Charcoal, Acta Chim. Slov., 52, 2005,73-79.

[95]. M.S. Chiou ,H.Y. Li , Adsorption behaviour of reactive dye in aqueous solution on chemical cross-linked chitosan beads, Department of Chemical Engineering, National Lien Ho Institute of Technology, Chemosphere, 50,2003, $1095-1105$.

[96]. Islem chaari, mongi feki, mouri medhioub, jalel bouzid, emna fakhfakh, fakher jamoussi, Adsorbent of a textile dye Indanthrene Blue RS (C.I. Vat Blue4) from aqueous solution onto smectite-rich clayey rock, Journal of hazardous materials,172(2-3),2009,16238 .

[97]. G. McKay , J.F. Porter and G.R. Prasad, The removal of dye colors from aqueous solutions by adsorption on low-cost materials, Water Air Soil Pollution 114, 1999,423-438.

[98]. Özacar andA.I. Sengil, Adsorption of metal complex dyes from aqueous solutions by pine sawdust, Bioresour. Technol. 96 ,2005, 791-795.

[99]. G.Annadurai ,R.S. Juang and D.J. Lee, Use of cellulose-based wastes for adsorption of dyes from aqueous solutions, J. Hazard. Mater. B,92,2002,263-274.

[100]. C.Rajeshwarisivaraj, Namasivayam and K. Kadirvelu, Orange peel as an adsorbent in the removal of acid violet 17 (acid dye) from aqueous solutions, Waste Manage, 21,2001, 105-110,

[101]. Ho Y.S. andG. McKay, Kinetic models for the sorption of dye from aqueous solution by wood, Trans. I Chem E B ,76,1998, $183-$ 191.

[102]. .S.D. Khattri and M.K. Singh, Colour removal from dye wastewater using sugar canedust as an adsorbent, Adsorption Science Technol. $17,1999,269-282$.

[103]. Khattri S.D. and Singh M.K., Colour removal from dye wastewater using sugar cane dust as an adsorbent, Adsorption Science Technol. 17, 1999, 269-282.

[104]. J.Eastoe and J.S. Dalton, Dynamic surface tension and adsorption mechanisms of surfactants at the air water interface, Advanced Journal of Collide interface science,85,2000,103-144.

[105]. H.Freundlich, Uber dye adsorption in solution, Journal of physical chemistry, 57, 1906,384-470.

[106]. .M.J. Tempkin and V. Pyzhev, Recent modifications to Langmuir isotherm, Acta Physiochim., URSS,12, 1940,217-222.

[107]. P. Cooper, Removing color from dyehouse waste waters: a critical review of technology available, J. Soc. Dyers Colorists ,109 ,1993, 97-100.

[108]. M.S. Chiou and H.Y. Li, Adsorption behaviour of reactive dye in aqueous solution on chemical cross-linked chitosan beads, Chemosphere $50,2003,1095-1105$.

[109]. R.S. Blackburn, Natural polysaccharides and their interaction with dye molecule: application in effluent treatment, Environmental Science Technology, 38, 2004,4905- 4909.

[110]. W. J. Weber Jr, C. B. Hopkins and R. Bloom Jr. Physicochemical treatment of wastewater, Journal of Water Pollution Control Federation, 42 (1), 1970,83. 